\title{
Are errors of commission better than errors of omission?
}

\author{
Leonard N. Girardi, MD
}

From the Department of Cardiothoracic Surgery, Weill Cornell Medical College, New York, NY.

Disclosures: Author has nothing to disclose with regard to commercial support.

Received for publication April 18, 2016; accepted for publication April 19, 2016; available ahead of print May 17, 2016.

Address for reprints: Leonard N. Girardi, MD, New York Weill Cornell Medical Center, 525 E 68th St, M404, New York, NY 10065 (E-mail: lngirard@med.cornell.edu).

J Thorac Cardiovasc Surg 2016;152:818-9

$0022-5223 / \$ 36.00$

Copyright (c) 2016 by The American Association for Thoracic Surgery

http://dx.doi.org/10.1016/j.jtcvs.2016.04.061

In this issue of The Journal of Thoracic and Cardiovascular Surgery, Weiss and colleagues ${ }^{1}$ present a small series outlining the diagnosis and management of floating thrombus in the aortic arch. They report on 10 patients who were seen with significant thrombus in the arch and summarize outcomes for those patients with this potentially lethal entity. On the basis of this limited experience, Weiss and colleagues ${ }^{1}$ espouse an aggressive policy of arch thrombectomy with acceptable short- and intermediate-term results.

New York cardiac surgery mythology says that Dr Frank Spencer would not graduate a fellow from his program unless he or she could come up with an operation to solve every pathology or postoperative complication. That philosophy morphed into the programmatic dogma that "errors of commission are better than errors of omission," a dogma that guided our behavior at Cornell for the last 3 decades. Clearly our Swiss colleagues would make Dr Spencer proud. Is commission the best treatment strategy for floating mural thrombus or are there patients for whom omission is the better way to go?

Aortic mural thrombus has been recognized in upwards of $9 \%$ of patients with arterial thromboembolism. ${ }^{2}$ Because a majority of patients are free of symptoms, it is difficult to quantify clinical relevance. A series of 10,671 consecutive autopsies, however, reported an incidence of thoracic aortic mural thrombus at $0.45 \%$. Nearly $17 \%$ had evidence of distal embolization, and in $6 \%$ that event was thought to be the cause of death. The arch and descending aorta were the most common sites of thrombus formation.

In the series of Weiss and colleagues, ${ }^{1} 80 \%$ had a presentation of arterial embolism. All underwent imaging with a combination of computed tomographic angiography and transesophageal echocardiography to identify the source of the event. Of the 8 patients with symptoms, 6 were treated with arch thrombectomy under deep hypothermic cardiac arrest. All did well, all were treated postoperatively with either warfarin anticoagulation or dual antiplatelet therapy, and none had evidence of recurrent thromboembolism a mean 17 months after surgery. Two additional patients were seen with cerebral embolic events and were

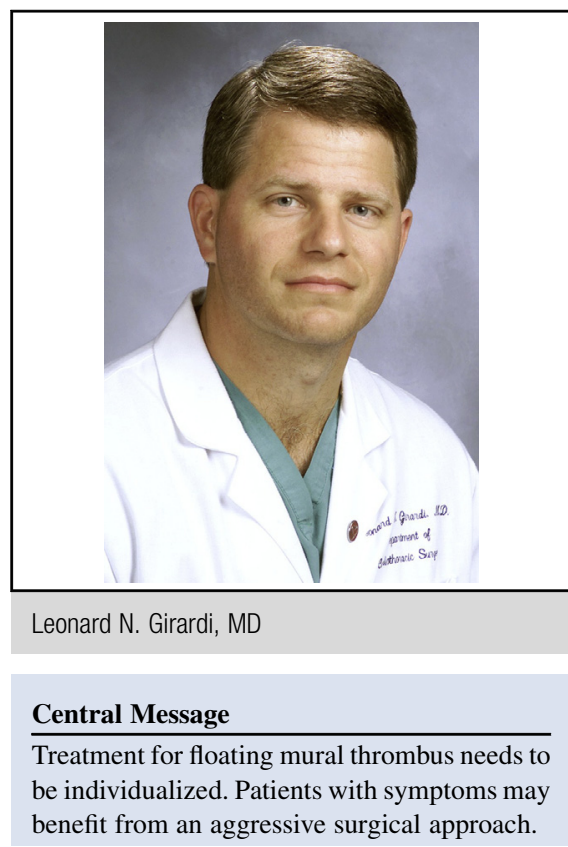

See Article page 810 .

initially treated with endovascular mechanical thrombectomy. Neither did well with that approach as sole therapy. Interestingly, the two symptom-free patients were treated with anticoagulation alone. Neither had recurrent emboli attributable to the arch thrombus.

For those patients with symptomatic floating arch thrombus, it seems reasonable to consider thrombectomy. With modern methods of cardiopulmonary bypass and cerebral protection, the risks of permanent neurologic deficit and mortality are substantially lower than the $25 \%$ chance of persistent thrombus or recurrent emboli seen in this population with anticoagulation alone. ${ }^{4}$ Perhaps retrograde cerebral perfusion, with its potential to flush debris out of the cerebral circulation, would be beneficial when the patient has had a cerebral embolism. Keep in mind, however, that this is still complex, invasive surgery. While Weiss and colleagues ${ }^{1}$ performed well in this small series, it was only 6 patients. One can easily imagine a myriad of complications that could arise if this aggressive algorithm were to be applied to a larger cohort with this disease. "Errors of commission" will occur. For those patients with symptoms who have prohibitive surgical risks, especially for those who have had cerebral emboli, a hybrid approach has been espoused, ${ }^{5}$ potentially creating even more "errors of commission." 
For those with asymptomatic thrombus incidentally discovered during routine imaging, it seems appropriate to use anticoagulation alone. The potential for recurrent events is the "error of omission" in this strategy, but it is difficult to support open-chest heart surgery in this scenario. A thorough search for etiology is mandatory, and a hypercoagulable workup should be included in the evaluation. Until there is more data from a larger cohort of patients, treatment for floating arch thrombus should be individualized.

\section{References}

1. Weiss S, Bühlmann R, von Allmen RS, Makaloski V, Carrel TP, Schmidli J, et al. Management of floating thrombus in the aortic arch. J Thorac Cardiovasc Surg. 2016;152:810-7.

2. Reber PU, Patel AG, Stauffer E, Müller WF, Do DD, Kniemeyer HW. Mural aortic thrombi: an important cause of peripheral embolization. J Vasc Surg. 1999;30:1084-9.

3. Machleder HI, Takiff H, Lois JF, Holburt E. Aortic mural thrombus: an occult source of arterial thromboembolism. J Vasc Surg. 1986;4:473-8.

4. Fayad ZY, Semaan E, Fahourn B, Briggs M, Tortolani AJ, D’Ayala M. Aortic mural thrombus in the normal or minimally atherosclerotic aorta. Ann Vasc Surg. 2013;37:282-90.

5. Verma H, Narendranadh M, Vora S, George RK, Tripathi RK. Contemporary management of symptomatic primary aortic mural thrombus. J Vasc Surg. 2014;60:1524-34. 